\title{
Que horas ela volta? Uma crônica cinematográfica
}

\author{
Maria Ignês Carlos Magno \\ Doutora em Ciências da Comunicação pela ECA-USP. Professora do mestrado em Comunicação \\ da Universidade Anhembi Morumbi e da Fundação Escola de Sociologia e Política de São \\ Paulo. \\ E-mail: unsigster@gmail.com
}

Resumo: O filme Que horas ela volta? (2015), de Anna Muylaert, e seu recebimento pela crítica e público, despertou o interesse em entender o porquê de uma história tão simples estar fazendo tanto sucesso. A proposta da resenha é pensar o filme sob a ótica da crônica. Uma crônica cinematográfica.

Palavras-chave: cinema brasileiro; crônica; comunicação audiovisual.
Abstract: The movie The second mother (2015), by Anna Myulaert was acclaimed by audience and critics and has aroused the interest in understanding why such simple story is so successful. The proposal of this review is to think the movie under the chronicle point of view.

Keywords: Brazilian cinema; chronicle; audiovisual communication.

$O$ cronista resgata a engrenagem da vida submersa na asfixia do tempo, e novamente a coloca diante de nossos olhos.

(Garcia, 2004, p. 79)

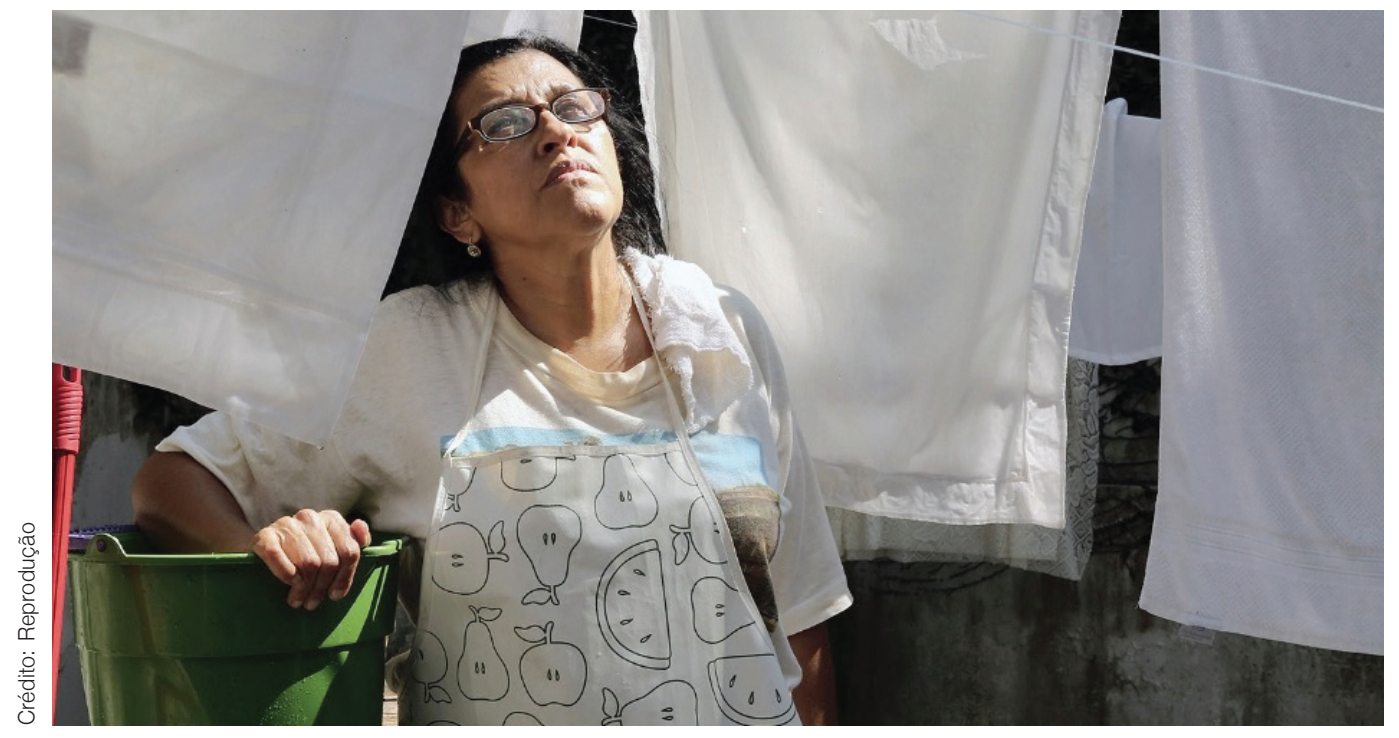




\section{INTRODUÇÃO}

Que horas ela volta?, de Anna Muylaert (2015) é um filme premiado. Percorreu vários festivais de cinema e conquistou dois prêmios importantes: o Prêmio do Público em Berlim e o Prêmio Especial do Júri na seção World Cinema Festival de Sundance. Filme selecionado para representar o Brasil na disputa pelo Oscar é natural que a crítica especializada fizesse análises, comentários, resenhas, ensaios. Assistir ao filme Que horas ela volta?, ler as críticas e as resenhas já escritas sobre ele; acompanhar os debates e as diferentes leituras que o filme provoca; ouvir relatos emocionados de alunos de uma escola noturna de alfabetização de jovens e adultos, leva-nos a muitas perguntas: por que um filme tão simples, por que uma história tão comum tem provocado tantas discussões e, ao mesmo tempo, reflexões? Por que esse impacto internacional e nacional? Perguntas que nos colocamos quando também nos percebemos no jogo proposto pela autora Anna Muylaert e como parte da trilogia que compõe uma obra, o público. Como grande parte do espectadores, fiquei emocionada, ri, indignei-me e pensei. Pensei o filme, pensei nas questões acima e, mesmo sabendo que a obra já é um sucesso de público e tem circulado nas salas de aula, gostaria de sugerir a possibilidade de discuti-lo sob a ótica da crônica. Uma crônica cinematográfica. Talvez nisso resida a força do filme. O cronista, nos dizeres de Maria Cecília Garcia: "não fala sobre tudo, sobre os grandes acontecimentos que mudam a vida, comovem as massas, afetam milhões de pessoas; ele fala daquilo que está muito próximo de nós, com o que tropeçamos todos os dias, e, justamente por isso, já não vemos mais"1. Anna Muylaert, ao falar do que está muito próximo de nós com o que tropeçamos todos os dias, e, justamente por isso, já não vemos mais, e ao transformar essa fala em imagens, obriga-nos a olhar o cotidiano e ver nesse cotidiano as complexas relações que envolvem o aparentemente insignificante, comum e natural da vida.

Nessa perspectiva, seguindo os ensinamentos de Antonio Candido de que "quando nos colocamos ante uma obra ou uma sucessão de obras, temos vários níveis possíveis de compreensão, segundo o ângulo em que nos situamos"2, e considerando o filme como o cronista que "capta a imagem do tempo em movimento [...] cujo valor é dado pelo que contém de significativo e não de curioso, já que sua função é revelar ao leitor (aqui o espectador) o que sempre esteve a seus olhos: as recorrências, as novas formas com que se reveste o velho,

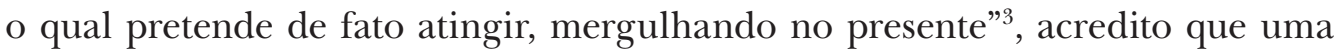
discussão sobre filme de Anna Muylaert valha a pena.

1. GARCIA, Maria Cecília, 2004 , p. 79.

2. CANDIDO, Antonio, s/d, p. 34

3. RONCARI, Luiz, 1985, p. 18.

\section{NO ROTEIRO - INÍCIO DO PROCESSO DE CRIAÇÃO}

Todo filme tem uma gênese e conta uma história. Entre a ideia inicial e a montagem final do filme está o roteiro. Como o filme, todo roteiro tem uma história. Quase nunca pensamos no seu processo. E nele está o início do processo de criação da obra cinematográfica. Escrito para ser transformado em 


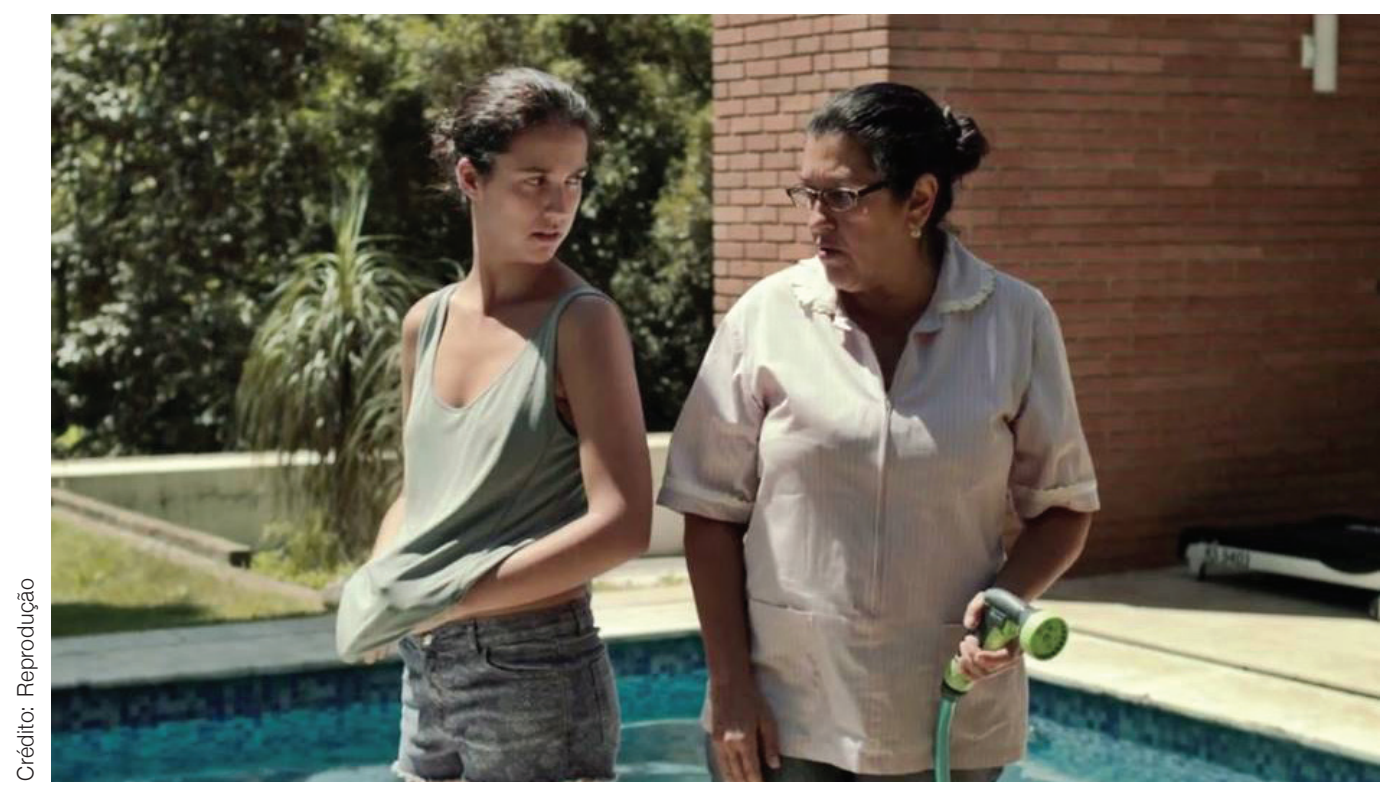

imagens, o exercício é duplo, o autor pensa o texto e as imagens como parte de um mesmo processo, ou parte de imagens que compõem suas memórias ou seus desejos e cria o texto. A construção das personagens é outra tarefa difícil se considerarmos que dependendo da temática da história é muito fácil cair nos estereótipos e dicotomias como a luta entre o bem e o mal, o bom e mau, o herói e o vilão. Outro elemento importante de conhecermos no processo de criação de um roteiro é a inspiração. Melhor dizendo, inspirações e referências. Inspirações literárias, casos da vida real, outras obras com a mesma temática, enfim, tudo o que possa ser considerado para contar uma boa história. E o mais importante, como contar a história pensada, como compor a temática central com as secundárias, que elementos formais utilizar para atingir o público? Todos esses elementos são essenciais para a construção de uma obra.

O filme conta a história de Val (Regina Casé), uma pernambucana que se mudou para São Paulo a fim de dar melhores condições de vida para sua filha Jéssica (Camila Márdila). Val deixa a filha na sua cidade de origem sob os cuidados de outra pessoa. Em São Paulo, torna-se babá de Fabinho e mora integralmente na casa dos patrões. Treze anos depois, a filha pede ajuda de Val para vir a São Paulo prestar vestibular. A história é simples, mas a ideia e a elaboração do roteiro não. A ideia central e a elaboração do roteiro acompanharam a cineasta e roteirista há mais de 20 anos. Na realidade, de acordo com a diretora, 27 anos. A história foi inspirada em duas personagens reais: Edna, babá de seu filho caçula, e Dagmar, que trabalhou na casa de seus pais quando ela era criança. Dagmar foi a inspiração para construção da personalidade de Val. O processo de elaboração do roteiro foi longo e passou por várias reformulações. Conta a autora que a primeira versão trazia apenas a visão da empregada e a filha Jéssica não vinha para São Paulo estudar, mas para ser cabelereira e depois se tornava babá. Fez laboratórios e mudou o 
rumo das personagens. Levou seis meses para encontrar o final. Só conseguiu a solução final para a história quando a diretora de fotografia lhe apresentou o conto "A casa tomada", do escritor argentino Julio Cortázar. Uma de suas inspirações. As demais inspirações foram: Cama adentro, filme argentino de 2004, e mais propriamente El Custodio, de Rodrigo Moreno, filme argentino de 2006. Nas palavras de Anna Muylaert, embora La Nana, filme chileno de Sebástian Silva, de 2009, seja bastante conhecido, não lhe serviu de inspiração. Outro dado interessante é a do título do filme. Inicialmente o nome seria A porta da cozinha, porque, segundo a autora, esse umbral separa a elite do popular no Brasil. No final, optou por outro título porque na realidade quer que todos o assistam.

O tema da empregada doméstica como protagonista não é inédito na filmografia brasileira e latino-americana. Na verdade, esse tema é recorrente em todos os países onde a colonização e a escravidão existiram. Aliás, uma das primeiras lições que os ingleses, os franceses, os alemães e os norte-americanos ensinavam quando colonizavam ou escravizavam os povos, era a capacidade de o serviçal se tornar invisível. Habitar a mesma casa e ser ao mesmo tempo invisível. Também o drama de Val e de Jéssica e de outros personagens que compõem a história do filme, como as diferentes ausências, as partidas, os deslocamentos de pessoas em busca de uma vida melhor nas cidades centrais do país, a invisibilidade dos trabalhadores, os afetos, os estranhamentos também não são novidade na filmografia brasileira. O que diferencia essa comédia dramática é o tratamento dado a esses temas, ou seja, a forma como esses elementos foram pensados e montados para contar a história. Um roteiro dialeticamente construído para mostrar as complexas relações humanas e de trabalho.

\section{DO ROTEIRO À CRÔNICA CINEMATOGRÁFICA}

Dos muitos níveis de compreensão possível de uma obra expostos por Antonio Candido ${ }^{4}$, em primeiro lugar estão os fatores externos que a vinculam ao tempo e se podem resumir na designação de sociais; em segundo lugar, o fator individual, isto é, o autor, o homem que intentou e realizou, e está presente no resultado; finalmente, o resultado, o texto, contendo os elementos anteriores e outros, específicos, que os transcendem e não se deixam reduzir a eles.

Os fatores externos ou os aspectos sociais que vinculam a obra ao tempo são mais facilmente observáveis. Um deles, o tema da ausência. A cena inicial da babá Val e o menino Fabinho brincando na piscina enquanto Val liga para sua filha para "dar um cheiro", dizer que está com saudades e saber se ela está sendo obediente, e em seguida a pergunta do menino sobre a hora que a mãe volta já nos situa no centro da história. Pela conversa com a filha pelo telefone, sabemos que ela deixou a menina com outra pessoa e veio para São Paulo. Pela pergunta de Fabinho, ficamos sabendo que é a empregada quem cuida integral-

4. CANDIDO, Antonio, p. $34, \mathrm{~s} / \mathrm{d}$. mente do menino. Os três vivem e sofrem as ausências. Mas Val não é a única 
que saiu de sua cidade natal para se deslocar para São Paulo e ganhar a vida para dar conforto à filha, essa também é a realidade de muitos de seus amigos que moram no bairro do Campo Limpo, para onde Val se desloca no final de semana com a empregada que trabalha na outra mansão. Os deslocamentos e as ausências são partes da realidade de muitos migrantes por todo o Brasil. A percepção da invisibilidade é um pouco mais sutil porque é o aparentemente natural. Val mora na casa dos patrões, habita o mesmo teto, é quase da família, está constantemente na casa, mas não pertence a ela como não pertence à família. Como exemplo mais direto dessa presença-ausência, podemos citar as cenas da festa de aniversário de Bárbara, quando Val serve as visitas sem ser vista, e durante uma entrevista sobre tendências e estilos em que Bárbara fala a uma jornalista e Val aparece desfocada no fundo na sala. As diferenças de classe não precisariam ser mencionadas dado que é o aspecto mais visível. $\mathrm{O}$ filme ia se chamar A porta da cozinha como relatou a autora porque a cozinha é o lugar onde fica a criadagem, o umbral que divide a elite do popular. No entanto, esse aspecto pode ser considerado um dos pontos-chave da trama.

Os conflitos de classe encobertos pela condição e submissão de Val afloram no momento em que a filha Jéssica chega para morar na mansão. A porta da cozinha não existe para Jéssica, ela não é e não se sente menor e nem se submete, é igual, não é empregada e questiona a maneira como a mãe, a quem chama de Val, é tratada. A chegada da filha, que pede para se instalar no quarto de hóspedes para estudar e que circula com naturalidade por todos os lugares da casa, irrita Bárbara, que faz questão de lembrar às duas que a casa ainda é dela.

Finalmente, apenas para citar algumas das temáticas tratadas no filme, são as relações afetivas, tão perturbadoras quanto as ausências. Apesar de tudo, os afetos existem por mais conflituosos que sejam. As circunstâncias da vida embolaram tudo. Val e Fabinho se amam, ela é realmente a sua segunda mãe (A segunda mãe é o título dado ao filme no exterior). Val ama a filha, mas a distância criou entre elas um estranhamento e os toques são contidos, os abraços resistentes. Bárbara gosta do filho, mas o distanciamento criado pelas ausências diárias também dificulta os abraços. Quando ela tenta dar um abraço e o filho se retira, ela reclama e diz que até Val, ou seja, a empregada, ele permite que o abrace, mas ela não pode chegar perto. O pai é um ausente total, não conseguimos nem saber se sente alguma coisa pelo filho. Val gosta dos patrões e eles dela, desde que as relações de hierarquia não sejam quebradas. Enfim, são alguns dos aspectos sociais que estão presentes no filme e que podemos identificar, até tecer análises aprofundadas sobre cada um.

O segundo nível de leitura e compreensão de uma obra, o fator individual, o autor, já foi em parte desenvolvido quando comentada a construção do roteiro. Mas é importante acrescentar que uma das marcas do cinema de Anna Muylaert é o olhar sobre o cotidiano, sobre pequenas histórias de família como Durval Discos, apenas para citar um como exemplo. Se a crônica, como nos lembra Roncari "usa e abusa da variedade dos pequenos gêneros, dos mais simples aos 
mais complexos, na sua composição: nos diálogos do cotidiano, retratos, tipos, cenas cômicas e dramáticas, versos, sonetos, relatos, narrativas, casos, comentários, contos, confissões, descrições líricas, sátiras e paródias [...]" e percebermos que muitos desses elementos não apenas aparecem nos seus filmes, mas são partes constitutivas deles, podemos tentar entender Anna Muylaert como uma cronista e seu cinema como uma crônica cinematográfica. O seu cinema é, como toda obra, "uma realidade autônoma, cujo valor está na fórmula que obteve para plasmar elementos não literários, impressões, paixões, ideias, fatos, acontecimentos que são a matéria-prima do ato criador" ${ }^{6}$. No entanto, e essa é a parte mais importante das três, a importância de sua obra (o filme) "quase nunca é devida à circunstância de exprimir seu aspecto da realidade, social ou individual, mas à maneira por que o faz. No limite, o elemento decisivo é o que permite compreendê-la e apreciá-la mesmo que não soubéssemos onde, quando, por quem foi escrita"7. Gostaria de retomar o início do texto e as questões colocadas para tentar fechar a leitura proposta nesta resenha.

Uma das questões era tentar entender por que um filme tão simples teve a recepção que teve e provocou tantas críticas e reflexões. Além de entender que um dos motivos se deva ao fato de ele ser uma crônica do cotidiano, daí o impacto que causa nas pessoas nos diferentes países onde o filme tem sido apresentado, quero chamar a atenção para a dialética interna do texto e para a composição do todo e das partes, e a maneira como a autora organiza a matéria-prima de seu filme. Apenas para exemplificar, se atentarmos para as duas partes do filme e os subtítulos que os acompanham, "minha filha voltou", e no final, "minha família voltou", podemos entender a dialética existente no roteiro e nas imagens. A história e a vida de Val junto com a família de Carlos, Bárbara e Fabinho seguia o fluxo normal das relações entre patrões e empregada. Após o telefonema da filha pedindo ajuda, dois fatos são essenciais na vida de Val: a vinda da filha que não via há 13 anos e como fazer já que não tinha casa própria para acolher Jéssica, mais a revolução que a vinda da filha provocaria na vida de todos. A vinda e o comportamento da filha na casa onde Val trabalhava é o ponto essencial tanto do estranhamento como da tomada de consciência. Jéssica era o elemento estranho na família e na vida de todos, inclusive de sua mãe. Sua interferência na vida da casa, das personagens e do espectador é direta. $\mathrm{O}$ estranho que atravessa e altera a aparente normalidade. De todas as mudanças, a mais forte é a de Val no tocante à personagem e na estrutura do filme. Se do ponto de vista social, ela torna visível todas as diferenças de classe e de comportamento, do ponto de vista formal a chegada da filha representará a superação da linearidade imaginada do filme, o rompimento do círculo do eternamente igual e insuperável. Anna rompe com o círculo do

5. RONCARI, Luiz, op. cit., p. 14

6. CANDIDO, Antonio, p. $34, s / d$.

7. Idem, ibidem. mesmo e da continuidade das relações sociais e de trabalho eternizadas desde a colonização. O mesmo destino da mãe: a existência de um filho, a vinda para os centros econômicos avançados em busca de trabalho para dar condições ao filho deixado para trás. Como cabelereira primeiro e depois como babá, nada mais óbvio e natural. No momento em que Val descobre que Jéssica tem um 
filho chamado Jorge e que o deixou no interior de Pernambuco para trabalhar em São Paulo, temos a superação, a dialética propriamente dita tanto no enredo como na estrutura do roteiro. Quando Val resolve que deixará o emprego para cuidar da filha e do neto que também desconhece e fala para a filha "buscar o Jorge", tudo muda. Jéssica sai de cena sorrindo ao saber que Val ajudaria a criar Jorge e o sorriso de Val tomando café na xícara que havia dado para a patroa e essa relegou, fecha o círculo. Nada mais a ligava à casa dos patrões desde que Fabinho, após ter fracassado no vestibular, havia ido para a Austrália fazer intercâmbio. Jéssica passa no vestibular, portanto, a história será outra, e os laços entre mãe e filha foram refeitos. A sua família estava de volta.

\section{REFERÊNCIAS}

CANDIDO, Antonio. Formação da literatura brasileira. Primeiro volume (1750-1836). São Paulo: Editora Martins Fontes S.A., s/d.

Literatura e Sociedade. Estudos de teoria e história literária. Rio de Janeiro: Ouro Sobre Azul, 2014.

GARCIA, Maria Cecília. Reflexões sobre a crítica teatral nos jornais. Décio de Almeida Prado e o problema da apreciação da obra artística no jornalismo cultural. São Paulo: Editora Mackenzie, 2004.

Que horas ela volta? Roteiro e direção: Anna Muylaert. 2015.

RONCARI, Luiz. A estampa rotativa na crônica literária. Boletim Bibliográfico da Biblioteca Mário de Andrade, v. 46, p. 9-16, 1985. 